\title{
Preschool In-service Teachers and Geometry: Attitudes, Beliefs and Knowledge
}

\author{
Zvia Markovits $^{1 \star}$ (D), Dorit Patkin ${ }^{2}$ (D)
}

\author{
${ }^{1}$ Faculty of Sciences, Kibbutzim College of Education Technology \& Arts, Tel Aviv, ISRAEL \\ ${ }^{2}$ Faculty of Education, Levinsky College of Education, Tel-Aviv, ISRAEL \\ *Corresponding Author: zviam@oranim.ac.il
}

Citation: Markovits, Z., \& Patkin, D. (2021). Preschool In-service Teachers and Geometry: Attitudes, Beliefs and Knowledge. International Electronic Journal of Mathematics Education, 16(1), em0619. https://doi.org/10.29333/iejme/9303

\begin{tabular}{|c|c|}
\hline ARTICLE INFO & ABSTRACT \\
\hline Received: 4 May 2020 & This study aims to explore in-service preschool teachers' attitudes towards and beliefs about geometry and its \\
\hline Accepted: 9 Sep. 2020 & $\begin{array}{l}\text { teaching and to investigate their knowledge of shapes and solids. The study uses a mixed descriptive approach } \\
\text { employing quantitative and qualitative research methods. Thirty-four Israeli preschool teachers of children aged } \\
\text { 3-6 from } 34 \text { different preschools and kindergartens participated in the study and responded to a questionnaire } \\
\text { comprised of closed and open items. Regarding their attitudes and beliefs, the preschool teachers were asked } \\
\text { about: the meaning of geometry; affinity for geometry, importance of geometry; need to use accurate } \\
\text { mathematical language, and about their enjoyment of engaging young children in activities connected with } \\
\text { learning geometry. As to the knowledge of shapes and solids, the preschool teachers were asked to describe or } \\
\text { define shapes and solids, name shapes and solids and distinguish between rectangles and other shapes. The } \\
\text { results illustrate that most of the preschool teachers like geometry or expressed a neutral position towards } \\
\text { geometry, but some hate geometry. Most of the preschool teachers comprehend the importance of engaging in } \\
\text { activities that relate to geometry in preschool and enjoy involving young children in activities connected with } \\
\text { learning geometry. As to the use of accurate language, most of the preschool teachers maintain that accurate } \\
\text { mathematical language should be applied when preschool children aged 3-6 deal with shapes and solids. Yet, only } \\
\text { about half of them believe that it is necessary to use accurate language when the children are at an earlier age. } \\
\text { Certain preschool teachers lack the knowledge to name shapes and solids, even those which are part the } \\
\text { mathematics curriculum for ages 3-6. They exhibited difficulties in using accurate mathematical language when } \\
\text { describing shapes and solids, and were influenced by the shapes' visual appearance rather than by their } \\
\text { definitions and properties. It is recommended that preschool teachers attend further development programs so } \\
\text { they can appropriately involve young children in activities connected to learning geometry, as required by the } \\
\text { curriculum. }\end{array}$ \\
\hline
\end{tabular}

Keywords: geometry, in-service preschool teachers, beliefs, shapes, solids

\section{INTRODUCTION}

Geometry is an integral part of our lives. We are surrounded by shapes and solids and interact with them on a daily basis. Shapes and solids are familiar to young children. They play with them as babies and continue using them as part of different games and building activities. Acquaintance with shapes and solids is important since it helps young children develop spatial orientation. In addition, playing with shapes and solids while exploring the relationships between them, establishes the foundations for logical thinking. Already at a very young age, children are able to develop extensive mathematical knowledge connected with everyday life (Ginsburg, Lee, \& Boyd, 2008). Geometric comprehension and spatial orientation develop in the early years. This is manifested for example when children, while playing, use names of shapes and solids in order to instruct their friends how to build a tower (Copley, 2000). Preschool teachers should help young children to develop their geometric understanding. Therefore, shapes and solids should be part of preschool teachers' activities with children. According to the National Council of Teachers of Mathematics (NCTM, 2000), instructional programs for K-12 should enable learners to "analyze characteristics and properties of two- and threedimensional geometric shapes and develop mathematical arguments about geometric relationships" (p. 96). Young children are expected to "recognize, name, build, draw, compare, and sort two and three-dimensional shapes; describe attributes and parts of two- and three-dimensional shapes; and investigate and predict the results of putting shapes together and taking them apart" (Clements \& Sarama, 2000, p. 82). Unfortunately, preschool teachers do not sufficiently engage young children in geometry-related activities. Clements \& Sarama (2011) argue that geometry is ignored or minimized in the early years. Moreover, they argue that preschool teachers all over the globe lack adequate training in geometry. 
Attitudes, beliefs and content knowledge play an important role in a teacher's ability to help young children in developing geometric understanding. Nevertheless, there is very little research focusing on preschool teachers' content knowledge of geometry and on their attitudes towards and beliefs about geometry. This study aims to investigate to what extent in-service preschool teachers have the content knowledge necessary for helping children in their geometry studies of shapes and solids, and to reveal preschool teachers' attitudes towards and beliefs about geometry and its teaching, as attitudes and beliefs may impact teachers' willingness to involve children in activities connected with the learning of geometry.

In 2010 the Israeli Ministry of Education published a National Math Curriculum for children aged 3-6. The curriculum comprises three chapters: the number concept, geometry, and quantitative concepts in everyday life. As far as geometry is concerned, children are expected, inter alia, and in line with Clements \& Sarama (2011), to identify, name, classify and draw two-dimensional shapes. The curriculum specifies circles, triangles, squares, rectangles, ellipses, quadrilaterals, pentagons and hexagons. As to solids (three dimensions), children are expected to name solids and recognize their faces. The curriculum indicates cubes, cylinders, spheres, cuboids, prisms, cones and pyramids (Ministry of Education, 2010). Preschool teachers are expected to implement the curriculum with all 3-6 year old children, include shapes and solids as part of everyday practice and to use accurate mathematical language since:

...learning at young ages is done also by imitating the teachers. Hence, it is important that teachers use accurate mathematical language so that children become accustomed to mathematical language and repeat it. Using accurate mathematical language will prevent or reduce formation of misconceptions (Ministry of Education, 2010, p. 9).

Although preschool teachers are expected to teach the math curriculum, they, in fact, receive very little preservice training in mathematics. In most of the colleges, only 1-3 semester courses (one semester course $=14$ weeks of 2 academic hours per week) are devoted to mathematics and its teaching in the early years. During this short time, the course lecturers must enhance teachers' mathematical knowledge, deal with methods of teaching mathematics to young children and also try to reduce fear, anxiety and negative feelings towards mathematics. With respect to geometry, the situation is more critical. Many prospective preschool teachers lack basic knowledge in geometry, and much time needs to be allocated to promoting their geometrical knowledge. Following their preservice studies, preschool teachers attend professional development courses, but most of them are not devoted to mathematics. The publication of the National Math Curriculum gave rise to two main questions which are the basis of this study: Do Israeli preschool teachers have the relevant content knowledge to facilitate appropriate teaching and to use accurate mathematical language associated with shapes and solids? Do they hold the attitudes and beliefs that motivate them to involve children in activities connected with learning geometry?

\section{THEORETICAL BACKGROUND}

\section{Engaging in Geometry Activities in the Early Years}

Acknowledgement of young children's abilities to grasp mathematical ideas together with emphasis on the importance of involving young children in activities connected with mathematics have rapidly grown in recent years (Baroody, Clements, \& Sarama, 2019; Clarke, Clarke, \& Roshe, 2011; Greenes, Ginsburg, \& Balfanz, 2004; Lee \& Ginsburg, 2007; Ginsburg et al., 2008; NAEYC, 2010; National Research Council, 2009). Greenes et al. (2004) describe children's competences when field testing the program Big Math for Little Kids: “...we observed children doing mathematical work at a higher level than we expected. Indeed, we were surprised at what the children managed to accomplish" (p. 164). Hachey (2013) adds that, "We now know that prior to elementary school, young children engage in surprisingly complex intuitive mathematical thinking with regard to numbers, geometry, measurement, algebraic thinking, and data analysis" (p. 419). However, most preschool teachers tend to engage young children more in language than in mathematics. This is due to the fact that they either believe that language is more important than mathematics at this age or they themselves have no interest in mathematics or are afraid of it (Copley, 2000; Lee \& Ginsburg, 2007; Ginsburg et al., 2008).

Among other mathematical topics, geometry gets the least attention (Clements \& Sarama, 2011; Moss, Hawes, Naqvi, \& Caswell, 2015). Clements, Sarama, Swaminathan, Weber and Trawick-Smith (2018) state that "... geometry is not always addressed in early childhood curriculum and even if included, it is not explored in the ways recommended by research" ( $p$. 7). Limited involvement in activities associated with geometry and measurement was found in a survey in which preschool teachers and managerial staff were asked to describe the mathematical activities in which children engaged. The 400 responses of the survey participants illustrated that $67 \%$ indicated activities of counting, $60 \%$ mentioned activities of sorting, $51 \%$ specified activities associated with number recognition, $46 \%$ mentioned activities dealing with patterning and $34 \%$ with number concepts. A lower percentage related to geometry: $32 \%$ pointed out activities of spatial perception, $16 \%$ indicated shapes and $14 \%$ measuring (Sarama, 2002; Sarama \& DiBiase, 2004). Similarly, a study conducted among young age practitioners (Rudd, Lampert, Satterwhite, \& Zaier, 2008) demonstrated lack of engagement in activities connected to learning geometry. The study examined the type of mathematical language and the frequency of its use among six preschool classes with children from birth until age 5 . As far as geometry was concerned, the study found that hardly any geometric concepts were applied and that only $1.2 \%$ of the observed mathematical language was dedicated to geometry. Mathematical language starts developing at a young age. Preschool teachers need to use accurate mathematical language, embracing such beliefs that would enable them to acknowledge the important role of mathematical language as a tool for developing mathematical ideas (Rubenstein \& Thompson, 2002; Whitin \& Whitin, 2003). Oberdorf and Taylor-Cox (1999) point to young children's numerous misconceptions about geometry, which may 
stem from lack of exposure to mathematical language. They state that young children may apply interchangeable words for 2-D shapes and 3-D solids but teachers should always use the correct names.

Mathematics in the early years "depends greatly on pre-kindergarten teachers, as they are the ones who ultimately determine what is implemented in their classroom" (Lee \& Ginsburg, 2007, p. 3). However, preschool teachers are not well prepared to engage in geometry with the children and this is probably one of the main reasons why geometry is overlooked (Clements \& Sarama, 2011). Moreover, Clements \& Sarama (2011) argue that greater importance must be assigned to preschool teachers' professional development for the purpose of engaging in geometry with children. They also emphasize that preschool teachers' knowledge of and beliefs about geometry should be enhanced.

\section{Preschool Teachers' Knowledge of Geometry}

Being versed in the relevant subject matter is one of the components of teachers' knowledge (Shulman, 1986). Preschool teachers need to have appropriate content knowledge in order to help young children in developing sound mathematical understanding. Nevertheless, Cullen (1999) argues that in the professional knowledge base of early childhood teachers, there should be greater emphasis on content knowledge. He maintains that, "It is difficult to see how teachers can acknowledge and extend young children's foundational domain knowledge if teachers themselves are not comfortable with the knowledge base of those domains (Cullen, 1999, p. 21).

Preschool teachers' level and quality of engagement in mathematics impacts the mathematics knowledge of preschool children (Zaslow, Tout, Halle, Whittaker, \& Lavelle, 2010). Brendefur, Strother, Thiede, Lane, and Surger-Prokop (2013) found that children whose preschool teachers attended a professional development program demonstrated higher mathematical abilities than children whose preschool teachers did not attend such a program. The children manifested higher abilities in different aspects of the number concept, problem solving, measurement and spatial abilities. Mathematical content knowledge of preschool teachers predicts their sensitivity to mathematical content. Higher mathematical content knowledge enables the preschool teachers to be better acquainted with the mathematical content involved in children's play scenarios (Oppermann, Anders \& Hachfeld, 2016).

However, the preparation of prospective preschool teachers and the professional development of in-service preschool teachers for teaching mathematics to young children seem to be very limited. Simpson and Linder (2014) conducted a study in the United Stated which investigated how and to what extend early childhood teachers are being prepared to develop mathematical abilities among young children. They stated that preschool teachers' professional development in mathematics is deficient. Moreover, they indicated that only a few of the professional development opportunities focus on developing mathematical content knowledge. It seems that this is the situation in many countries. In a study conducted in Poland (Klim-Klimaszewska \& Narazuk, 2017) among 150 preschool teachers, geometry topics used by the teachers in their classes were recorded over a period of eight months. The results illustrated that there was no systematic use of geometric concepts by most of the teachers. The researchers pointed out that during their graduate studies only 20-30 hours were devoted to mathematical education in preschool and that only $10 \%$ of the participants took a supplementary course in mathematics after graduation. Youmans, Coombs and Colgan (2018) conducted a survey among 130 early childhood teachers in Canada and found that most of them did not receive any training to teach mathematics to children in their early years. Moreover, the early childhood educators felt less comfortable with teaching geometry and spatial sense in comparison to teaching the number concept. In a study conducted in Sweden (Björklund \& Barendregt), 147 early childhood teachers were asked about their habits of working with mathematics. The results illustrated that number sense was a regular occurrence in teachers' interactions with the children, and more than $70 \%$ of the teachers said that they include numbers in daily interactions. However, as to geometry, it was found that only $42 \%$ of the teachers regularly used shapes and patterns. The researchers argued that "...geometrical shapes and patterns are not phenomena teachers work with intentionally" (Björklund \& Barendregt, 2016, p. 369). Difficulties in teaching geometry stemming from lack of knowledge, competences and skills for teaching this topic were found in a study that explored Turkish preschool teachers' perspectives of teaching geometry in kindergarten classes. The researchers recommended enhancing preschool teachers' awareness of misconceptions, suggesting that development programs for preschool teachers should be designed to improve their knowledge and skills (Inan \& Dogan-Temur, 2010). Another study conducted in Turkey (Korkmaz, \& Şahin, 2019) examined the pedagogical content knowledge concerning shapes among 84 preservice preschool teachers. The participants were presented with several vignettes, each of which included a common geometry mistake found among young children. The results suggested that in many of the vignettes presented to them, the preservice teachers were able to partially identify the mistakes, but were unable to suggest solutions for helping children to eliminate those mistakes. Lee (2017) conducted a study with 30 preschool teachers in South Korea. He found that the teachers' low abilities did not enable them to interpret and enhance children's mathematical thinking. As to geometry, the teachers' ability to identify mathematical situations connected with shapes received a score of only $46.7 \%$ in comparison with $\mathbf{8 6 . 7 \%}$ for the situations connected to number sense. Preschool teachers in Israel encountered more difficulties related to solids than to 2-D geometric shapes. While preschool teachers managed to identify examples and non-examples of geometric shapes, such as triangles and circles, they found it difficult to identify examples or non-examples of cylinders. As to definitions, they were able to define triangles but had difficulties in defining circles and cylinders (Tsamir, Tirosh, Levenson, Barkai, \& Tabach 2015). The understanding of the concepts of cylinder and prism was studied in a research conducted in Turkey among 72 prospective early years' teachers. The results showed that the participants had difficulty in defining both concepts. They used general attributes in their definitions, such as 'three-dimensional', and not critical attributes (Ulusoy, 2019). Moss et al. (2015) created a professional development model designed to support preschool teachers in teaching and learning geometry and spatial reasoning in early years' classes. They state that early years preschool teachers typically lacked the content knowledge and confidence needed for teaching geometry and spatial reasoning. 


\section{Preschool Teachers' Attitudes and Beliefs}

Attitudes and beliefs play an important role in teachers' practices and in the content their students learn (Leder, Pehkonen \& Torner, 2002; Stipek, Givvin, Salmon \& MacGyvers, 2001; Thompson, 1992). A positive relationship between preschool teachers' attitudes towards mathematics and the mathematical development of kindergarten children as well as the selection of activities in mathematics areas in which teachers chose to engage the children was reported by Çelik (2017).

Many prospective preschool teachers manifest negative feelings of hate and fear and even anxiety with respect to mathematics (Gresham, 2007; Markovits, 2012; Markovits \& Forgazs, 2017; Zacharos, Koliopoulus, Dokimaki \& Kossoumi, 2007). If these feelings are not addressed during their years of study, math anxiety may expected to be found among in-service preschool teachers as well. Aslan (2013) conducted a study in which he compared prospective and in-service preschool teachers' mathematics anxiety and beliefs about mathematics for young children. He found that in-service preschool teachers manifested more math anxiety than prospective preschool teachers. In his study of 31 Head Start teachers, Geist (2015) investigated their attitudes toward mathematics and the effect thereof on how and what they taught in their classes. The findings suggested that there was a relationship between math anxiety and negative attitudes towards mathematics. Moreover, the study illustrated that these feelings affected teachers' curriculum planning choices as well as their ability to involve young children in mathematics activities. Beliefs regarding mathematics teaching efficacy were investigated by Takunyaci and Takunyaci (2014) among 95 preschool teachers. Their study indicated that preschool teachers hold low efficacy beliefs about teaching mathematics. For example, $44 \%$ of the preschool teachers were not sure whether they possessed the necessary skills for teaching mathematics, and $81 \%$ of them thought that they would teach mathematics ineffectively.

On the other hand, some studies report much more positive views of preschool teachers' beliefs and self-confidence in teaching math to young children. Chen, McCray, and Adams (2014) conducted a survey among 346 preschool teachers. They found much more positive beliefs and self-confidence regarding teaching mathematics to young children than previously reported. Keles, Tas, and Aslan (2016) used metaphors to investigate 50 prospective preschool teachers' perceptions of mathematics and its teaching to young children. They found that most of the metaphors used by the teachers were positive (88.8\%), suggesting that they had positive beliefs about mathematics and its teaching.

The theoretical background emphasizes the importance of involving young children in activities connected with learning geometry and presents the need for appropriate content knowledge as well as appropriate attitudes towards and beliefs about geometry among preschool teachers. Moreover, the theoretical background points out young children's lack of engagement in activities connected with learning geometry as well as difficulties preschool teachers have in teaching geometry in many different countries. This study investigates to what extent Israeli preschool teachers have the content knowledge necessary for helping children to develop the concepts of shapes and solids, and reveals teachers' attitudes towards and beliefs about geometry and its teaching to 3-6 year old children.

\section{METHODOLOGY}

\section{Research Questions}

In order to reveal preschool teachers' attitudes toward geometry and beliefs about geometry and to better understand their knowledge about shapes and solids, a mixed descriptive approach was used which employed quantitative and qualitative research methods. The following research questions were the basis of this study:

a. What attitudes do preschool teachers hold toward geometry?

b. What beliefs do preschool teachers hold about teaching geometry to 3-6 year old children?

c. What beliefs do preschool teachers hold regarding the necessity of using accurate language when engaging with children on the topic of solids?

d. What knowledge do preschool teachers possess regarding shapes and solids?

\section{Participants}

A total number of 34 preschool teachers participated in the study. Their average age was 40, ranging from 31 to 53 years old. Their average seniority as preschool teachers was 14.2 years and the seniority ranged between six and 30 years. The preschool teachers attended one of two teacher development programs (not specifically devoted to mathematics), one in the north and one in the center of Israel, and were chosen to take part in this study since they represented 34 different preschools from different parts of the country covering the north to the south of Israel. The participants were teachers of 3-6 year old children. They were asked to participate in the study during one of the sessions of the development programs and all of them agreed to do so.

\section{The Questionnaire}

The questionnaire, developed for this study, contains items relating to attitudes towards and beliefs about geometry and its teaching in preschool as well as items regarding knowledge of shapes and solids.

\section{Attitudes towards and beliefs about geometry and its teaching in preschool}

This part of the questionnaire comprised eight items. Two of the items were open-ended, asking the preschool teachers to write down the first thing that crossed their mind when the word geometry was mentioned and to write down what geometry meant to them. In three of the items the participants were asked whether they liked geometry, enjoyed involving young children 
in activities connected with learning geometry and, the importance they attributed to geometry. These items were ranked according to a Likert-type scale. In each of these items the preschool teachers had to indicate their answer on a scale of $1-5$, " 5 " indicating "like very much," "enjoy very much" and "very important," and " 1 ' indicating "hate very much," "do not enjoy at all," and "not important at all." In each of these items the participants were also asked to explain their choice. In three other openended items the preschool teachers were required to express their opinion about the need to accurately use mathematical language when dealing with solids.

\section{Knowledge of shapes and solids}

This part of the questionnaire comprised four items. The first item was open-ended and the preschool teachers were asked to describe or define two shapes: a triangle and a rectangle, and two solids: a cuboid and a pyramid. In the second item they were asked to name nine shapes and in the third item the preschool teachers were asked to name eight solids. In the fourth item, the participants had to distinguish between rectangles and other given shapes, then identify the inclusion relations between rectangles and squares and explain their answer.

\section{Procedure and Categorization of Responses}

The questionnaire was administered to the participants during one of the sessions of the teacher development programs they attended. The teachers received explanations about the aim of the study and were informed that they could refuse to respond to the questionnaire. However, all the teachers approached agreed to participate. The time needed to complete the questionnaire ranged between 40 and 50 minutes.

The analysis of the responses was carried out according to the item type. For the items whose answers were on the Likert-type scale, the mean value of the preschool teachers' choices was calculated. For the items in which naming of shapes and solids was required, the responses were coded based on the name suggested by the teachers for each shape and solid. The responses were coded as "correct," if the correct name of the shape or the solid was given, "general" when teachers did not specify the particular name but rather gave a more general answer naming, for example, a kite as a polygon, and "incorrect answer," when an incorrect name was written. Open-ended items or explanations given by the preschool teachers were coded according to categories derived from the participants' responses. These categories were established by the researchers separately for each of the open-ended items and for each item that asked for an explanation; the participants' responses were coded by both researchers based on these categories.

\section{RESULTS}

In this chapter we present the responses given by the preschool teachers. First, the results obtained by analyzing the items related to teachers' attitudes towards and beliefs about geometry and its teaching in preschool are presented. Then the findings associated with the preschool teachers' knowledge of shapes and solids are presented.

\section{Attitudes towards and Beliefs about Geometry and its Teaching in Preschool}

\section{Beliefs about geometry}

Most of the participants indicated that the "first thing that crossed their mind when someone said the word geometry" was shapes. Twenty-nine preschool teachers (85\%) wrote the word shapes, or gave names of common shapes. The preschool teachers hardly mentioned the term solids and only four of them referred to solids in addition to shapes. Four participants (12\%) mentioned proofs in their answers and five others (15\%) indicated other concepts associated with geometry, such as: lines, angles and measurement. The total percentage is above $100 \%$ since some of the participants wrote more than one word in their answer.

In the second item, where the preschool teachers were asked "what does geometry mean to you," the answers were quite similar to their answers in the previous item and again, as in the previous item, some participants gave more than one answer. Most (23 participants, 68\%) said that geometry was shapes or the theory of shapes and four participants (12\%) said that geometry was a branch of mathematics. Solids were mentioned in nine responses $(26 \%)$ while other concepts and components related to geometry, such as: measurements, lines, volume, and calculations, were mentioned in 11 responses (32\%). In preschool, many of the objects children play with are solids. Hence, their preschool teachers see solids and engage with solids on a daily basis. However, for most of the preschool teachers, geometry was associated with shapes much more than with solids.

\section{Attitudes towards geometry}

Table 1 presents the mean value and the distribution of responses to the item "Do you like geometry?"

Table 1. "Do you like geometry?": Mean and distribution of responses

\begin{tabular}{ccccccc}
$\begin{array}{c}\text { The item } \\
(\mathrm{n}=34)\end{array}$ & Mean & $\begin{array}{c}\mathbf{5} \\
\text { Like very much }\end{array}$ & $\begin{array}{c}\mathbf{4} \\
\text { Like }\end{array}$ & $\begin{array}{c}\mathbf{3} \\
\text { Neither like nor hate }\end{array}$ & $\begin{array}{c}\mathbf{2} \\
\text { Hate }\end{array}$ & $\begin{array}{c}\mathbf{1} \\
\text { Hate very much }\end{array}$ \\
\hline Do you like geometry? & 3.39 & 7 & 8 & 11 & 5 & 2 \\
\hline
\end{tabular}

Table 1 illustrates that the mean is somewhat higher than 3, the neutral position. The distribution of answers showed that only 15 preschool teachers (44\%), liked geometry. About one third (32\%) expressed a neutral position and seven preschool teachers $(21 \%)$ mentioned they hated geometry while five of them said they hated it and two hated it very much. Thus, seven preschool teachers expressed hate towards a subject area they are supposed to teach. 
Explanations were received from 26 participants. The explanations of about one third of the respondents (31\%) revealed the relationship between their negative or neutral attitudes towards geometry and their own experience at school. For example: "In my experience at school the study of geometry was without joy and fun. Hence, when I think about geometry I think about something complicated, not light, heavy" or "Don't like it, a negative memory from school."

Most of the preschool teachers, who expressed a neutral position with respect to liking or hating geometry, specified it was due to the fact that they could deal with or would like to deal with geometry as teachers of young children but not with the geometry they had studied at school. For example: "I love basic geometry but I encounter difficulties when geometry becomes more complex," or "at school I was not good in geometry, I did not understand part of the explanations. Things got increasingly more complicated. Today when I realize the importance of the subject, I want to learn geometry and to learn about the way of teaching it to children."

Some of the preschool teachers who said they liked geometry (indicated 4 or 5) explained it by the fact that they had always succeeded in this field. For example: "I never failed. It seemed to me like matching one Lego block to another." Others said that geometry could be taught in an experiential manner, for example: "I like it not because I scored 100 at school (I never achieved that) but because I realized that knowledge of geometry can be acquired through experience and inquiry." Certain preschool teachers said they liked geometry following an in-service training course they had attended: "The in-service training course I attended last year offered me many insights about this field. It also made me like this subject since I understood how essential it was to teach it in early years".

\section{Beliefs about engaging children in activities connected with learning geometry}

Table 2 illustrates the mean value and the distribution of answers to the items regarding enjoyment and importance of involving young children in activities connected with the learning of geometry. In the first item " 5 " indicates "enjoy very much" whereas " 1 " indicates "do not enjoy at all." In the second item " 5 " indicates "very important" and " 1 " indicates "not important at all."

Table 2. Enjoyment and importance of involving children in activities connected with learning geometry: Mean and distribution of responses

\begin{tabular}{cccccc}
\hline The item $(\mathrm{n}=34)$ & Mean & $\mathbf{5}$ & $\mathbf{4}$ & $\mathbf{3}$ & $\mathbf{2}$ \\
\hline $\begin{array}{c}\text { Do you enjoy involving young children in activities } \\
\text { connected with learning geometry? }\end{array}$ & 4.09 & 11 & 14 & 0 \\
\hline $\begin{array}{c}\text { Do you think it is important to involve young children } \\
\text { in activities connected with learning geometry? }\end{array}$ & 4.3 & 14 & 15 & 4 & 0 \\
\hline
\end{tabular}

As can be seen from Table 2, twenty-nine preschool teachers (85\%) thought it was important or very important to involve young children in activities connected with the learning of geometry. Twenty-five of the teachers (74\%) enjoyed or greatly enjoyed involving the children in activities related to geometry. The others chose to express a neutral position towards these items: $12 \%$ (4 teachers) expressed neutrality towards the importance of involving young children in geometry activities and about a quarter ( 8 teachers, 24\%) expressed this position towards the pleasure derived from involving young children in geometry activities. None of the preschool teachers expressed negative beliefs. These mean values were much higher than the mean values of liking geometry, 4.09 and 4.3 versus 3.39. The findings illustrated that most of the preschool teachers understood the importance of involving young children in geometry activities, although some of them did not particularly like geometry while others even hated it.

Explanations for the item: Do you enjoy involving young children in activities connected to learning geometry? received responses from 26 preschool teachers. Nineteen of the respondents (73\%) indicated that they enjoyed or greatly enjoyed involving young children in geometry activities. They explained that in preschool this engagement was pleasant and fun for the children and that geometry was part of everyday life. For example: "Our world and our environment are built of shapes and lines. Together with the children I can re-experience geometry in a playful and pleasurable way and make the children aware that geometry can actually be found everywhere." Preschool teachers who manifested a neutral position (27\%) focused their argument on insufficient knowledge of geometry or apprehension of making geometry a negative experience as it probably had been for them as learners, in the past. For example: "If I can expose them to the subject in an experiential way and help them discover it through hands-on activity I would enjoy being a partner to that," or "I think I can enjoy it but first I need to enhance my knowledge of geometry. Now I do not deal with geometry very much."

In the item asking about the importance of involving young children in activities connected with learning geometry, 28 preschool teachers (82\%) gave reasons for their answers. Twenty-five (89\%) wrote that such involvement was important or very important. In their arguments they indicated that "geometry is everywhere around us and it is an integral part of our life, similar to language and numbers," or "because it is an area to which we are exposed throughout our entire life, since childhood." Another kind of argument made to support the importance of involving children in geometry activities was due to an unsuccessful personal experience with the subject, something they wished to change. For example: "If I, as a preschool teacher, have a problem with learning geometry in an experiential and enjoyable way then I would like to change this experience for the children and deliver it to them so that they feel it's fun." Three explanations (11\%) were offered by preschool teachers who expressed a neutral position. One said she would engage in geometry activities only if the child showed an interest in the subject. Two others pointed out that it was as important to engage in geometry as in other subjects. 


\section{Beliefs about the need to use accurate mathematical language}

The preschool teachers were requested to express their opinion about the need to apply accurate mathematical language already in the early years in order to distinguish between 2-D and 3-D shapes. The first item was, "In your opinion, when playing games, such as the game presented in Figure 1, with children aged six months to three years, should the game pieces be named square, circle, triangle, and so on, or they should be referred to by their accurate name, i.e. cuboid, prism, etc.? Explain your answer."

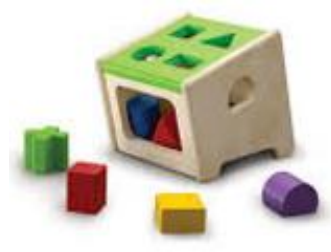

Figure 1. Children's game

Thirty-three preschool teachers replied to this item. Only about half of them (17 participants, 52\%) maintained that accurate language should be applied already in the early years and that the game pieces should be referred to by names of solids and not of shapes. They explained that it was important to use accurate names in order to avoid misleading the children and confusing them later on. For example: "The child internalizes the name already the first time and it is going to be difficult or irreversibly damaging to change the term which has already been absorbed" or "it is preferable to refer to the game pieces by their name in order not to mislead the children." Thirteen preschool teachers (39\%) said that game pieces should be referred to by names of shapes. They argued that young children should first become acquainted with the basic terms or that young children were not yet at a developmental stage which allowed them to cope with names of solids, e.g., "They should be called square and circle. At this initial stage I would refer to them using a more general name and in more familiar language"; or "the children should become familiar first with the names of the basic shapes." This item raised one preschool teacher's awareness of the need for accurate geometry language. She said: "We do call them square and triangle, but we should call them a cuboid, a prism, and so on." Another preschool teacher explained that this depended on the game pieces, namely "it depends if we name the shapes of the holes or the solids which we insert into them." Yet another preschool teacher claimed that they should not be named at all: "The very practice is the important part!! We don't have to push and try making them learn."

In the second item the participants were asked: "When preschool children (aged 3-6) engage in building, do we have to accurately name the blocks the children use for building, e.g. cuboid, cone, prism and others? Explain your answer." All the participants responded to the item. Thirty-one (91\%) maintained that the blocks should be accurately named. Twenty-six explained their answer, saying that in their opinion accurate names should be applied because children at this age are capable of understanding the concept of 3-D. Moreover, they can understand the explanation about 2-D and 3-D and distinguish between a shape and a solid. For example: "The internalization level of children at this age is good so children should accurately know the building parts in early years"; or "yes, as we name a green apple and a red apple so it is important to give an accurate name." The other five preschool teachers who believed that the parts should be accurately named did not explain their answer. Two preschool teachers believed that accurate names of the blocks were not required but did not provide a reason. One of them was the preschool teacher who said in the previous item that it was not necessary at all to name shapes and solids in preschool. One preschool teacher found it difficult to decide and said this depended on children's age and developmental stage. She said in the previous item that in the early years, solids should be referred to by names of shapes.

In the third item the preschool teachers were told that "there are some preschools where the building area is called "the cubes area." They were requested to express their opinion about this issue and give reasons for it. Thirty-three preschool teachers responded to this item. Twenty-seven of them (82\%) believed that the name "cubes area" was unsuitable. One said that in her preschool it was called "the cubes space" but she knew this was incorrect. Four preschool teachers (12\%) had no problem with the name whereas the item itself increased the awareness of two preschool teachers (6\%). It made one of them understand that the name "the cubes area" was misleading. She said: "Actually when I think about it now I find it misleading. We can call it the building area in order not to confuse the children with incorrect terms. Not all the solids are cubes." Another preschool teacher stated that "this is indeed food for thought." Many of preschool teachers who stated that the name "the cubes area" was unsuitable suggested other names, such as: "the building with solids area," "the building space," "the building area," "the solids space." The preschool teachers said that in this area there were not only cubes, but other solids as well and this might mislead the children. For example: "the name might confuse the children since in the "cubes area" there are, for example, also cylinders which are not considered cubes. Nevertheless, in the preschools where I've worked, geometry was not emphasized and therefore I did not experience any confusion." In her answer, this preschool teacher described the lack of emphasis on engagement in geometry in preschool.

\section{Knowledge of Shapes and Solids}

In this section, we first describe the findings obtained from the items dealing with the ability to describe shapes and solids, then those regarding the ability to name shapes and solids and finally, the findings dealing with the relations between quadrilaterals. 


\section{The ability to describe shapes and solids}

The preschool teachers were asked to complete four assertions: "a triangle is....," "a rectangle is...," "a cuboid is...," and "a pyramid is...." These two shapes and the two solids can be found in almost every preschool and are part of the Israeli National Mathematics Curriculum for children aged 3-6 (Ministry of Education, 2010). In all items no instruction was given whether to write or draw, but most of the teachers gave a verbal answer.

"A triangle is..."

Thirty-three teachers responded to this item, 25 of them (76\%) gave a verbal answer and eight (24\%) drew a triangle. All the teachers who drew a triangle drew a "prototypical" triangle, acute-angled and in a "typical" position, like the triangle displayed in Figure 2.

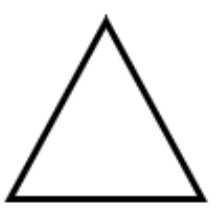

Figure 2. A prototypical triangle in a "typical" position

According to the definition, a triangle is a 3-sided polygon. Out of the 25 preschool teachers who gave a verbal answer, 10 teachers (30\%) described the triangle in a manner matching the definition. Twelve teachers (37\%) used the words "three sides" and the word "shape" but did not relate to the fact that the shape must be a closed shape. The other three teachers (9\%) gave some kind of an "intuitive definition" which complied more with the way in which young children describe a triangle and did not use an accurate mathematical language: " 3 straight lines connected at 3 vertices," "a shape consisting of 3 lines and 3 angles which are interconnected," "a solid with 3 sides."

"A rectangle is..."

The same 33 preschool teachers also responded to this item. Twenty-seven (87\%) gave a verbal answer whereas six (13\%) drew a rectangle. In this item as well, all the teachers who drew the rectangle drew a "prototypical" one, i.e., a rectangle with a pair of horizontal sides and a pair of vertical sides, the horizontal sides being longer than the vertical ones, in a "typical" position like the rectangle in Figure 3.

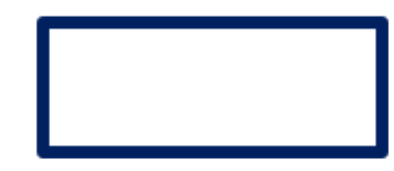

Figure 3. A prototypical rectangle in a "typical" position

According to the definition, a rectangle is a quadrilateral with four right angles (or four equal angles). Some other definitions can be used, for example: a polygon with two pairs of opposite sides which are parallel and equal and with a right angle, or a parallelogram with one right angle.

Of the 27 preschool teachers who gave a verbal answer, four (15\%) related to the rectangle's sides and angles. They defined it as a polygon or quadrilateral with two long sides which are parallel and two short parallel sides, connected by four $90^{\circ}$ angles. Twelve other respondents (44\%) gave some kind of partial definition and related only to the fact that the opposite sides should be parallel or equal. They disregarded the requirement of having a right angle (or having four equal angles) which is a necessary condition for being considered a rectangle. Nine of them specified that a rectangle was a polygon consisting of two pairs of parallel, equal, short lines and two pairs of parallel, equal and long lines. Three others referred to the fact that the opposite sides were equal: "two short and equal and two long and equal." These findings suggest that according to most of the preschool teachers, the rectangle consists of two short sides and two long sides, an indication which prevented the inclusion relation between a square and a rectangle. The remaining 11 participants (41\%) mentioned that a rectangle was a shape with four sides and four vertices, a description applying to every quadrilateral.

$$
\text { "A cuboid is..." }
$$

According to the definition, a cuboid is a prism with two opposite faces that are identical rectangles called bases. The vertices of the bases are joined to form lateral faces which are also rectangles. We did not necessarily expect to receive such an exact definition; however, we did expect the preschool teachers to describe the cuboid using geometric language or to draw it. Only twenty-five of the preschool teachers (74\%) responded to the item, a considerably lower number than the 33 teachers who answered parallel items about shapes. Two preschool teachers chose to draw, and correctly drew, a "prototypical" cuboid. The other 23 teachers gave verbal answers. Four (17\%) were close to the definition, for example: "a solid consisting of 4 rectangles and 2 squares," "prism whose base is a rectangle," "this was a joining of 6 quadrilaterals, perhaps rectangles," "a solid in space with two square faces and four rectangular faces." The answers given by the other 19 preschool teachers (83\%) illustrated the difficulty in properly describing a cuboid, e.g., "a solid with four faces and volume," "a solid with faces." Moreover, some answers indicated the difficulties encountered while using accurate geometric language, such as: "a square with a 'depth'," "a 3-D square," "a 3-D rectangle," "a shape with dimensions." 
"A pyramid is..."

According to the definition, a pyramid is a solid built of some polygon which is called the base and a point, called the apex, not in the plane of the base that is connected with line segments to each vertex of the base. The pyramid is named for its base. If the base is a triangle, the pyramid is called a tetrahedron; if the base is square, the pyramid is called a square pyramid and so on. Twenty-six preschool teachers (76\%) responded to this item. Three used a drawing: one drew a square pyramid, another drew a tetrahedron. The third probably related to a tetrahedron as well but drew a triangle. The other 23 teachers gave a verbal answer. The answer of four teachers (17\%) was somewhat close to the definition of a pyramid, referring to a tetrahedron or a square pyramid. For instance: "A square base - with triangles as faces which converge into one vertex." or "a 3-D solid with one vertex and a square-shaped base." Another preschool teacher did not describe the pyramid but pointed out from where she knew it: "An ancient structure, discovered by the Egyptians in ancient times, whose form recalls a triangle." In this item, similar to the previous one, the other 18 preschool teachers (78\%) encountered difficulty in verbally describing a solid they would encounter when engaging with preschool children in geometry activities, as well as difficulty in applying accurate geometric language. For example: "a 3-D triangle," "a triangle-shaped solid with a vertex," "a triangle with depth and a wide base," "a triangle shape with volume," "a geometric solid with depth," "a triangle with several dimensions," "a solid with faces and pointed end," "a triangleshaped 2-D solid." The findings illustrated that for most of the preschool teachers the association of a pyramid was that of a tetrahedron. The probable reason is that they connected the geometric pyramids to the pyramids built in Egypt, which are among the stories Israeli children learn in preschool.

\section{The ability to name shapes and solids}

The preschool teachers were given nine shapes (see Figure 4) which they were asked to name. All the shapes are polygons with the exception of one which is an ellipse.

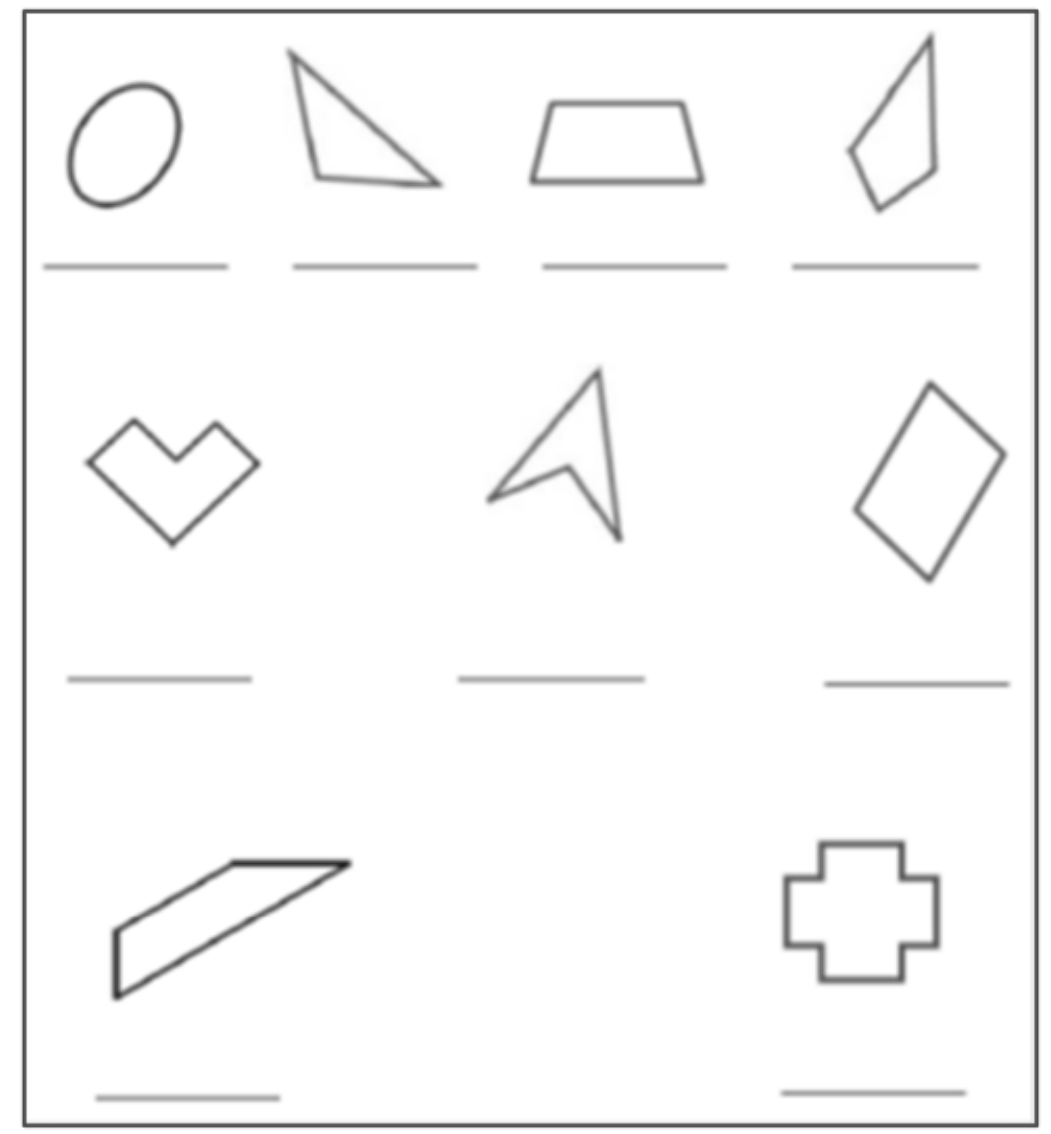

Figure 4. Shapes

The polygons comprised one triangle, five quadrilaterals - two being trapezoids (an isosceles trapezoid in a "typical" position and an oblique trapezoid), two kites (a convex kite and a non-convex kite) and one parallelogram. Moreover, the drawings included a non-convex hexagon and a non-convex 12-sided polygon. The ellipse, triangle and the "common" quadrilaterals are familiar shapes which are included in the preschool curriculum.

Table 3 presents the preschool teachers' answers: the number of preschool teachers who gave a correct answer (they named the shape by its "private" name and not by a general name, e.g., they named a kite a kite and not a polygon); the number of teachers who gave a "general" answer (e.g., called a kite a quadrilateral or a polygon); the number of teachers who answered incorrectly; and, the number of teachers who did not respond. 
Table 3. Distribution of responses: Naming shapes $(\mathrm{N}=34)$

\begin{tabular}{|c|c|c|c|c|}
\hline Shape & Correct answer & $\begin{array}{l}\text { "General" } \\
\text { answer }\end{array}$ & Incorrect answer & $\begin{array}{l}\text { Did not } \\
\text { respond }\end{array}$ \\
\hline Ellipse & 32 & & 2: Egg (1), circle (1) & \\
\hline Trapezoid & 28 & & 4: Kite (2), parallelogram (1), rectangle (1) & 2 \\
\hline Kite & 12 & $\begin{array}{l}\text { 2: Quadrilateral (1), polygon } \\
(1)\end{array}$ & $\begin{array}{l}\text { 16: Rhombus (12), trapezoid (1), parallelogram } \\
\text { (1), lines (1), diamond (1) }\end{array}$ & 4 \\
\hline Triangle & 31 & 2: Polygon (2) & 1: Lines (1) & \\
\hline Hexagon & 8 & 15: Polygon (15) & 2: Closed shape (1), square (1) & 9 \\
\hline Parallelogram & 19 & $\begin{array}{l}\text { 5: Quadrilateral (4) polygon } \\
\text { (1) }\end{array}$ & 5: Rhombus (4), rectangle (1) & 5 \\
\hline Non-convex kite & 3 & $\begin{array}{l}\text { 19: Polygon (12), } \\
\text { quadrilateral ( } 7)\end{array}$ & 3: "Broken" triangle (1), lines (1), rhombus (1) & 9 \\
\hline Trapezoid & 17 & 4: Polygon (4) & 2: Parallelogram (2) & 11 \\
\hline 12-sided polygon & 1 & 4: Polygon (4) & $\begin{array}{c}\text { 6: Decagon (2), square (1), cube (1), octagon (1), } \\
\text { quadrilateral (1) }\end{array}$ & 23 \\
\hline
\end{tabular}

Most of the preschool teachers correctly named the ellipse and the triangle (32 and 31 respectively, out of 34). The parallelogram and the trapezoid were correctly named by about half the teachers (17 and 19 respectively). As for the other shapes, the teachers encountered difficulties in naming them correctly. Thus, only eight preschool teachers correctly named the hexagon, only three correctly named the non-convex kite and only one wrote "a 12-sided polygon" with reference to the last shape. The column "did not respond" in Table 3 indicates also the degree of preschool teachers' knowledge. Most named the familiar shapes or those which seemed familiar to them. For example, all the preschool teachers gave an answer for the ellipse and the triangle (although some gave an incorrect or general answer). The number of preschool teachers who did not respond increased when the shape appeared less familiar, e.g., the trapezoid, hexagon or non-convex kite. In particular, it grew in the case of the 12-sided polygon which $68 \%$ of the teachers ( 23 teachers) did not name at all.

It is interesting to look at the incorrect names given by the teachers. Some of these names are not geometric names at all, such as an egg or a diamond, and are similar to names preschool children use. In part, incorrectly naming the shapes probably stems from being unacquainted with their definitions and/or properties and from basing the description on visual perception. The convex kite was the shape which led the highest number of teachers (16), almost 50\%, to give an incorrect answer. Twelve of them maintained that this was a rhombus, perhaps because of the position which reminded them of a rhombus in a "typical" position.

The preschool teachers were asked to name the eight solids presented in Figure 5. These include a cylinder and a cone which are not polyhedrons. Among the polyhedrons, the cube, cuboid and pyramid are common solids. In addition, a prism and an octahedron were also presented.

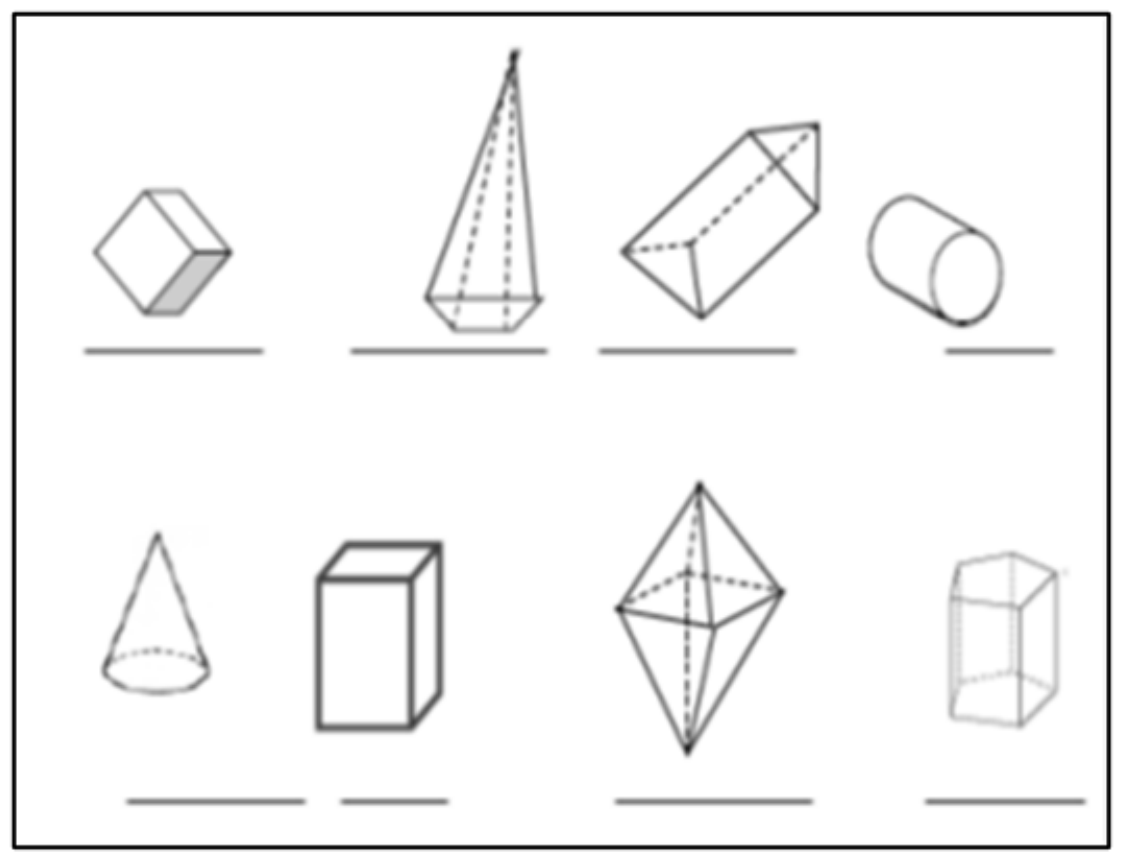

Figure 5. Solids

Table 4 shows the preschool teachers' answers. Most of them correctly named the common solids: cylinder, cube, cone and cuboid (31, 31, 27 and 25 respectively). Less than half of the respondents (16) correctly named the pyramid and the prism. The difficulty was particularly prominent in naming the pentagonal prism and the octahedron. Only eight respondents correctly named the pentagonal prism. Although it is one of the five regular solids, the findings showed that the preschool teachers were not familiar with the octahedron and hence, none of them named it correctly. In most of the incorrect answers, the preschool teachers used names of other solids. For example, six of them referred to the pentagonal prism as a cuboid. 
Table 4. Distribution of responses: Naming solids ( $\mathrm{N}=34)$

\begin{tabular}{cccc}
\hline Solid & Correct answer & "General" answer & Incorrect answer \\
\hline Cylinder & 31 & 2: Solid (2) & 3: Pyramid (2), quadrilateral prism (1) \\
\hline Prism (triangular) & 16 & 4: Prism (2), cone (1), 3-D trapezoid (1) & \\
\hline Pyramid & 16 & 1: Quadrilateral prism (1) & 14 \\
\hline Cube & 31 & 13: Quadrilateral prism (6), pentagonal geometric solid (4), \\
3-D pentagon (1) & 13 \\
Prism (pentagonal) & 8 & 2: Solid (2) & 8: Prism (3), double pyramid (2), kite (1), pyramid (1), \\
quadrilateral prism (1) & 4: Cube (4) \\
\hline Octahedron & 0 & 24 & 4: Prow of a ship (2), prism (1), quadrilateral prism (1)
\end{tabular}

\section{The ability to identify the relationships between quadrilaterals}

The preschool teachers were presented with 11 shapes (Figure 6) and were asked to identify all the rectangles among the given shapes. The definition of a rectangle applies to four shapes: 2, 3, 6 and 10 . Shape 2 is a rectangle in a "typical" position; in shape 6 the rectangle is oblique; and, in shape 10 the rectangle is narrow and long. Shape 3 is a "special" rectangle, namely a square. This item embodies three distractors which, to a certain extent, visually bring to mind the rectangle: the trapezoid (shape 7), the parallelogram (shape 5) and shape 9 which is a closed shape with "rounded" corners.

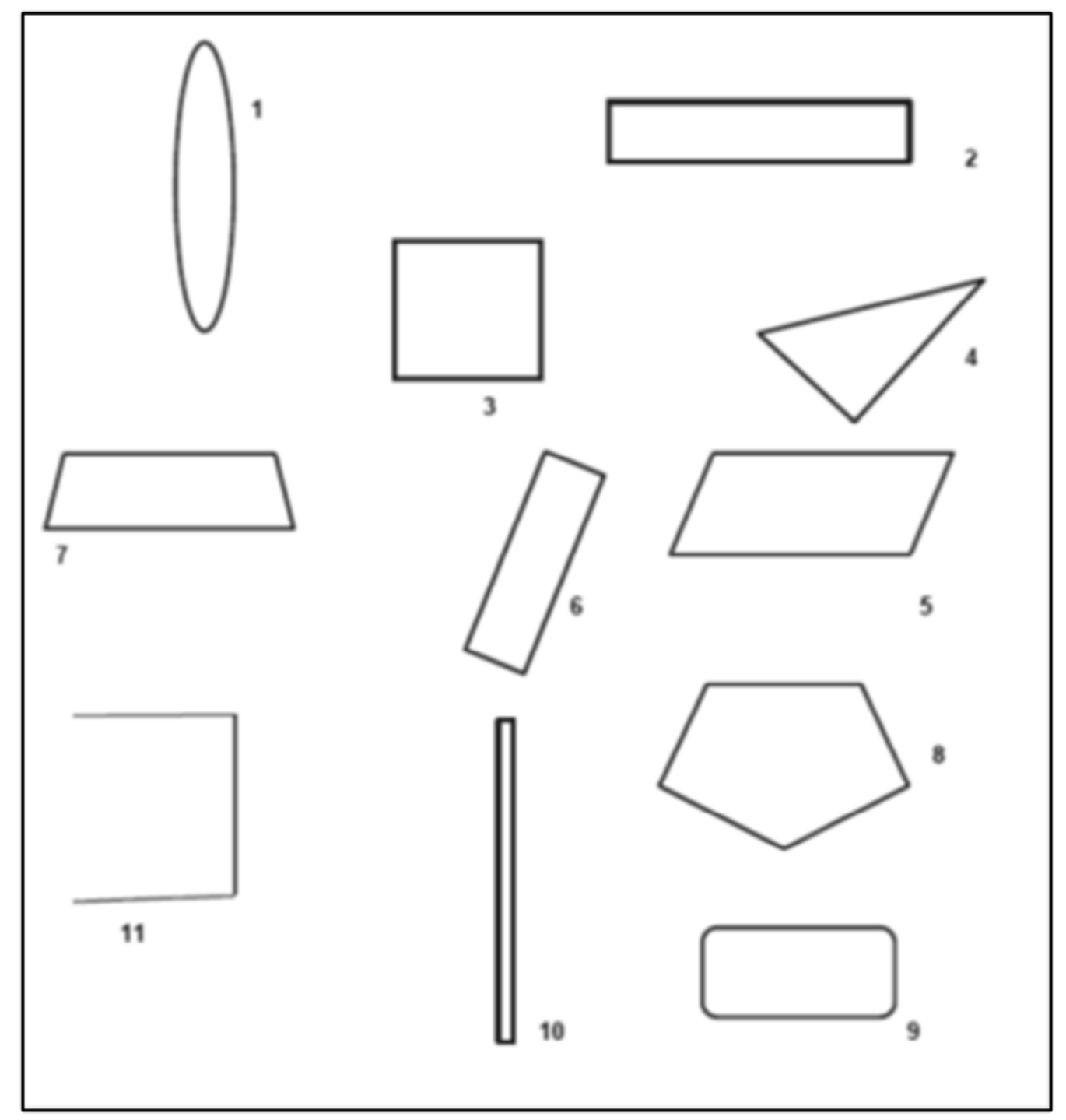

Figure 6. The 11 shapes

All the preschool teachers responded to this item. However, only six of them (18\%) gave a full answer and indicated the four shapes which complied with the definition of a rectangle. Eleven teachers (32\%) indicated only three shapes - 2, 6 and 10 - but did not indicate the square as a rectangle. Ten respondents (29\%) pointed out that there were only two rectangles (shape 2 and shape 6), not taking into consideration the square and the narrow and long rectangle. One participant said that only the 
"prototypical" rectangle (shape 2) was a rectangle. The other six preschool teachers (18\%) added and indicated more shapes as rectangles. Three of them also specified the shape with the "rounded corners" (shape 9) as a rectangle. Three others added the parallelogram (shape 5), and one indicated also the isosceles trapezoid (shape 7).

The fact that many of the preschool teachers did not indicate the square as a rectangle was due to lack of knowledge of the inclusion relations in the family of quadrilaterals. These teachers, as well as the teachers who did not indicate shape 10 - the "narrow and long" rectangle - or indicated the parallelogram, trapezoid and the shape with the "rounded corners" as a rectangle, probably based their statement on the visual appearance and did not relate to the definition.

A follow-up item related to the square (shape 3), asked whether this shape was a rectangle. We thought that if we explicitly asked about this relation perhaps it would remind the teachers of the inclusion relations. Only six preschool teachers (18\%), those who indicated the square as a rectangle in the previous item, responded correctly to this item. However, only two of them gave correct arguments: "Every square is a rectangle because it complies with the definition of the rectangle." The other four gave incorrect reasons, such as: "Every rectangle is also a square" or "because it has a pair of equal parallel sides." They automatically recalled the statement mentioned both here and in the previous item but failed to understand what these words implied.

The 28 preschool teachers (82\%) who gave an incorrect answer and argued that the shape was not a rectangle, explained it by saying that the drawing was a square, adding it was commonly known that a square has equal sides. Hence, this was not a rectangle "because in a rectangle the sides are not equal and this is in contrast to a square." That is, the definition of the rectangle which they recalled said that a rectangle had two long sides and two short sides. This prevented them from referring to the square as a rectangle, a perception matching their answers to the item in which they were asked to describe a rectangle.

\section{DISCUSSION AND CONCLUSIONS}

This study explored Israeli preschool teachers' attitudes towards and beliefs about geometry, their engagement in geometryrelated activities during early years' education, as well as their knowledge of shapes and solids. The results illustrate that many teachers lacked knowledge of shapes and solids. This was also manifested in cases wherein such knowledge related to the naming of shapes and solids, an integral component of the activities in which teachers are meant to involve their preschool children. Lack of geometrical knowledge was found among preschool teachers in research studies conducted in different countries (e.g., Inan \& Dogan-Temur, 2010; Ulysoy, 2019) and was emphasized by Clements and Sarama (2011). Shapes and solids constitute a central area of activity in which preschool children engage. Basic knowledge about shapes and solids implies the ability to distinguish between examples and non-examples, manifested by the ability to correctly name shapes and solids. Preschool teachers found it difficult to name less familiar polygons. However, they also encountered difficulties in naming polygons that should be familiar and are part of the children's Math Curriculum (Ministry of Education, 2010). Thus, only about one third of the preschool teachers could refer to a kite by its designated geometrical name and only half of them referred to a trapezoid by its formal name. This also applied to the naming of solids. Only half of the preschool teachers could name the pyramid and the prism although both are names of solids which preschool children should learn, according to the math curriculum. The lack of geometric language was also manifested on items the preschool teachers were asked to describe: a triangle, rectangle, cuboid and pyramid. It is hard to understand how these preschool teachers communicate in appropriate mathematical language with the children when they themselves have difficulties (Cullen, 1999) which may lead to misconceptions among the young children (Oberdorf \& Taylor-Cox, 1999). Only a few teachers were able to correctly name most of the shapes and the solids. Of the 17 shapes presented to them, just four teachers correctly named more than 12 shapes and solids.

Furthermore, the findings of this study suggest that the majority of the preschool teachers did not ground their explanations about shapes in their properties but mainly in their appearance. This was prominent in their answers regarding a triangle and rectangle, in which most of the preschool teachers drew or verbally described a "prototypical" triangle or rectangle. Moreover, this was illustrated in the items dealing with the inclusion relations among the family of quadrilaterals. It is likely to assume that they exposed the children to mainly "prototypical" geometric shapes and thus, shapes in their various positions were covered only to small extent. Relying on the appearance of the shape rather than on its properties is one of the developmental stages of young children's comprehension of geometry (Aslan \& Aktas-Arnas, 2007) and this was found among some of the preschool teachers as well.

The kinds of attitudes towards and beliefs about mathematics which preschool teachers hold are probably connected to their experience as students in mathematics classes at school, to their experience with the courses and programs they have studied as prospective preschool teachers and as in-service teachers, and to their experiences while engaging in mathematics with young children. School, and especially high school, plays an important role in shaping teachers' attitudes towards and beliefs about geometry. For most of the teachers geometry means shapes. For only a few of them was geometry also associated with solids or with other geometric topics. Although in elementary school a large part of geometry studies is dedicated to solids, the preschool teachers remembered high school geometry, which was indeed mostly dedicated to shapes. As preschool teachers they should be familiar with solids, which constitute a large part of geometry. Nevertheless, shapes are still more associated with geometry in their minds.

The majority of the preschool teachers deemed involving young children in activities connected with the learning of geometry to be important, namely, awareness of the need to engage in geometry does exist. But only few stated that they liked geometry. Most exhibited a neutral position, while seven of them said they hated geometry. A lack of affinity for mathematics among preschool and prospective preschool teachers has been reported in a number of studies (e.g., Markovits \& Forgazs, 2017). The low mean value for the item of liking geometry might stem from the preschool teachers' association of geometry with what they had 
studied at school and not necessarily with the geometry in which preschool children engage. Although this was a likely possibility, the analysis of the results indicated that the preschool teachers' beliefs about geometry were essential. In this study, a relationship was found between liking or hating geometry and between enjoying involving children in geometry-related activities, and the importance attributed to the need for such involvement. All the preschool teachers who selected " 4 " or " 5 " on the item regarding affinity for geometry, indicating they liked or greatly liked geometry, also selected " 4 " or " 5 " on the item asking about enjoyment in involving young children in activities related to learning geometry and the importance they attributed to this involvement. That is, those who liked geometry also enjoyed or greatly enjoyed engaging in activities that enhanced knowledge about geometry with young children. Moreover, they deemed it important or highly important to do so. The fact that seven preschool teachers hated or strongly hated geometry was extremely worrying. The attitude of these seven preschool teachers in most cases was neutral regarding the issue of enjoyment as well as the issue of importance attributed to involving young children in activities connected with learning geometry. Perhaps in their answer to the first item the preschool teachers meant they hated school geometry. Nevertheless, this hate affected the enjoyment they derived from engaging in geometry with young children as well as their comprehension of the importance attributed to this issue. The findings led to the conclusion that their hate of geometry in one way or another influenced their wish and willingness to plan geometry-related activities for the children in their class. It most certainly had an impact on their ability and readiness to identify occasional situations wherein children could deal with geometry (Geist, 2015).

Children in the early years learn by imitation (Ministry of Education, 2010). They imitate their preschool teachers and the language they use. Hence, it is highly important to use accurate mathematical language (Rubenstein \& Thompson, 2002; Whitin \& Whitin, 2003). Indeed, most of the preschool teachers concurred that it would be incorrect to refer to the building area as the "cubes area." Furthermore, most of them agreed that the names of solids should be used when children aged 3-6 used solids for the purpose of building. However, only 17 preschool teachers maintained that accurate language should be properly used when talking with toddlers up to the age of 3 . For these preschool teachers using proper mathematical language depended on the children's age. It would probably have never occurred to them to use their mother tongue in an incorrect or inaccurate manner when young children were concerned. Correcting it later, when the children grew up, would entail the need to eradicate mistakes which had already been assimilated. Yet, these preschool teachers saw no problem in thinking that incorrect or inaccurate language could be applied in the case of mathematics, due in all likelihood to not being aware that this may result in misconceptions among children (Oberdorf \& Taylor-Cox, 1999).

Planning and distributing a National Math Curriculum for preschool children is extremely important. Yet, this is only the first step. The Israeli National Math Curriculum was circulated a decade ago (Ministry of Education, 2010). Nevertheless, the results of this study indicate that preschool teachers did not receive enough training to teach geometry and that they need to attend further development programs so they can properly engage in geometry activities with the children, according to curricular requirements (Klim-Klimaszewska \& Narazuk, 2017; Youmans, Coombs \& Colgan, 2018). Geometry is an integral part of children's daily life and thus, engaging in activities meant to enhance understanding of geometry is the basis for further learning and for developing children's thinking. Preschool teachers who do not plan enough such activities or teach geometry using inaccurate terms or explanations deprive the children of the opportunity to develop their geometrical thinking. Thus, in-service teacher development programs as well as courses for prospective teachers should be carefully designed in order to upgrade preschool teachers' knowledge as well as change their attitudes towards and beliefs about geometry.

The issue of geometry among preschool teachers is most essential and needs further research. Our study, although based on the responses of only 34 preschool teachers in Israel, seems to add some significant information regarding preschool teachers' knowledge of shapes and solids and their attitudes towards and beliefs about geometry. Interviews with preschool teachers, in addition to the use of written questionnaires, would facilitate better understanding of their attitudes towards and beliefs about geometry and its teaching in preschool. Likewise, the effectiveness of carefully developed in-service programs as well as courses for prospective teachers should be further investigated.

\section{REFERENCES}

Aslan, D. (2013). A comparison of pre-and in-service preschool teachers' mathematical anxiety and beliefs about mathematics for young children. Academic Research International, 4(2), 225- 230.

Aslan, D., \& Aktas Arnas, Y. (2007). Three-to six-year-old children's recognition of geometric shapes. International Journal of Early Years Education, 15(1), 83-104. https://doi.org/10.1080/09669760601106646

Baroody, A. J., Clements, D. H., \& Sarama, J. (2019). Teaching and learning mathematics in early childhood programs. In C. Brown, M. McMullen \& F. N. K. (Eds.), Handbook of early childhood care and education, (pp. 329-354), Hoboken, NJ: Wiley Blackwell Publishing. https://doi.org/10.1002/9781119148104.ch15

Björklund, C., \& Barendregt, W. (2016). Teachers' pedagogical mathematical awareness in Swedish early childhood education. Scandinavian Journal of Educational Research, 60(3), 359-377. https://doi.org/10.1080/00313831.2015.1066426

Brendefur, J., Strother, S., Thiede, K., Lane, C., \& Surger-Prokop, M. J. (2013). A professional development program to improve math skills among preschool children in head start. Early Childhood Education Journal, 41, $187-195$. https://doi.org/10.1007/s10643-012-0543-8

Çelik, M. (2017). Examination of the Relationship between the preschool teachers' attitudes towards mathematics and the mathematical development in 6-year-old preschool children. Journal of Education and Learning, 6(4), 49-56. https://doi.org/10.5539/jel.v6n4p49 
Chen, J. Q., McCray, J., Adams, M., \& Leow, C. (2014). A survey study of early childhood teachers' beliefs and confidence about teaching early math. Early Childhood Education Journal, 42(6), 367-377. https://doi.org/10.1007/s10643-013-0619-0

Clarke, D., Clarke, B., \& Roche, A. (2011). Building teachers' expertise in understanding, assessing and developing children's mathematical thinking: the power of task-based, one-to-one assessment interviews. ZDM-The International Journal on Mathematics Education, 43(6-7), 901-913. https://doi.org/10.1007/s11858-011-0345-2

Clements D. H., \& Sarama, J. (2000). The earliest geometry. Teaching Children Mathematics, 7(2), 82-86.

Clements, D. H., \& Sarama, J. (2011). Early childhood teacher education: the case of geometry. Journal of Mathematics Teacher Education, 14(2), 133-148. https://doi.org/10.1007/s10857-011-9173-0

Clements, D. H., Sarama, J., Swaminathan, S., Weber, D., \& Trawick-Smith, J. (2018). Teaching and learning Geometry: early foundations. Quadrante, 27(2), 7-31.

Copley, J. V. (2000). The young child and mathematics. Reston, VA, and Washington, DC: National Council of Teachers of Mathematics and the National Association for the Education of Young Children.

Cullen, J. (1999). Children's knowledge, teachers' knowledge: Implications for early childhood teacher education. Australian Journal of Teacher Education, 24(2), 13-27. https://doi.org/10.14221/ajte.1999v24n2.2

Geist, E. (2015). Math anxiety and the "math gap": How attitudes toward mathematics disadvantages students as early as preschool. Education, 135(3), 328-336.

Ginsburg, H. P., Lee, J. S., \& Boyd, J. S. (2008). Mathematics Education for Young Children: What It Is and How to Promote It. Social Policy Report. 22(1), 1-22. https://doi.org/10.1002/j.2379-3988.2008.tb00054.x

Greenes, C., Ginsburg, H.P., \& Balfanz, R. (2004). Big math for little kids. Early Childhood Research Quarterly, 19, $159-166$. https://doi.org/10.1016/j.ecresq.2004.01.010

Gresham, G. (2007). A study of mathematics anxiety in pre-service teachers. Early Childhood Education Journal, 35(2), 181-188. https://doi.org/10.1007/s10643-007-0174-7

Hachey, A. C. (2013). The early childhood mathematics education revolution. Early Education and Development, 24, $419-430$. https://doi.org/10.1080/10409289.2012.756223

Inan, H. Z., \& Dogan-Temur, O. (2010). Understanding kindergarten teachers' perspectives of teaching basic geometric shapes: a phenomenographic research. ZDM Mathematics Education, 42, 457-468. https://doi.org/10.1007/s11858-010-0241-1

Keles, O., Tas, I., \& Aslan, D. (2016). Metaphor Perceptions of Pre-Service Teachers towards Mathematics and Mathematics Education in Preschool Education. Educational Research and Reviews, 11(14), 1338-1343. https://doi.org/10.5897/ERR2016.2727

Klim-Klimaszewska, A., \& Nazaruk, S. (2017). The scope of implementation of geometric concepts in selected kindergartens in Poland. Problems of Education in the 21st Century, 75(4), 345-353.

Korkmaz, H. I., \& Şahin, Ö. (2019). Preservice preschool teachers' pedagogical content knowledge on geometric shapes in terms of children's mistakes. Journal of Research in Childhood Education, 1-21. https://doi.org/10.1080/02568543.2019.1701150

Leder, G. C., Pehkonen, E., and Torner, G. (2002). Beliefs and hidden variable in mathematics education. Dordrecht: Kluwer. https://doi.org/10.1007/0-306-47958-3

Lee, J. E. (2017). Preschool teachers' pedagogical content knowledge in mathematics. International Journal of Early Childhood, 49(2), 229-243. https://doi.org/10.1007/s13158-017-0189-1

Lee, J. S., \& Ginsburg, H. P. (2007). What is appropriate mathematics education for four-year-olds? Pre-kindergarten teachers' beliefs. Journal of Early Childhood Research, 5(1), 2-31. https://doi.org/10.1177/1476718X07072149

Markovits, Z. (2012). Beliefs hold by preschool prospective teachers towards mathematics and its teaching. Procedia - Social and Behavioral Sciences, 11, 117-121. https://doi.org/10.1016/j.sbspro.2011.01.045

Markovits, Z., \& Forgasz, H. (2017). Prospective preschool teachers' beliefs about mathematics before and after a mathematics teaching course. Journal of International Scientific Publication: Educational Alternatives, 15, 80-89.

Ministry of Education (2010). Mathematics curriculum for kindergarten in the state and state-religious education frameworks. Jerusalem: Curricula Department, Ministry of Education. [Hebrew]

Moss, J., Hawes, Z., Naqvi, S., \& Caswell, B. (2015). Adapting Japanese Lesson Study to enhance the teaching and learning of geometry and spatial reasoning in early years classrooms: a case study. ZDM Mathematics Education, 47, 377-390. https://doi.org/10.1007/s11858-015-0679-2

NAEYC - National Association for the Education of Young Children. (2010). Early childhood mathematics: Promoting good beginnings. Washington, DC: NAEYC. Retrieved from https://www.naeyc.org/files/naeyc/file/positions/psmath.pdf

National Council of Teachers of Mathematics (2000). Principles and Standards for School Mathematics. Reston: Va.: NCTM.

National Research Council. (2009). Mathematics learning in early childhood: Paths toward excellence and equity. Washington, DC: National Academy Press.

Oberdorf, C. D., \& Taylor-Cox, J. (1999). Shape up! Teaching Children Mathematics, 5(6), 340-345.

Oppermann, E., Anders, Y., \& Hachfeld, A. (2016). The influence of preschool teachers' content knowledge and mathematical ability beliefs on their sensitivity to mathematics in children's play. Teaching and Teacher Education, 58, $174-184$. https://doi.org/10.1016/j.tate.2016.05.004 
Rubenstein, R. N., \& Thompson, D. R. (2002). Understanding and supporting children's mathematical vocabulary development. Teaching Children Mathematics, 9(2), 107-113.

Rudd, L. C., Lambert, M. C., Satterwhite, M., \& Zaier, A. (2008). Mathematical Language in Early Childhood Settings: What Really Counts? Early Childhood Education Journal, 36, 75-80. https://doi.org/10.1007/s10643-008-0246-3

Sarama, J. (2002). Listening to teachers: Planning for professional development. Teaching Children Mathematics, 9, 36-39.

Sarama, J., \& DiBiase, A. M. (2004). The professional development challenge in preschool mathematics. In D. H. Clements \& J. Sarama (Eds.), Engaging young children in mathematics: Standards for early childhood mathematics education (pp. 415-448). Mahwah, NJ: Lawrence Erlbaum Associates.

Shulman, L. S. (1986). Those who understand knowledge growth in teaching. Educational Researcher, 15(2), 4-14. https://doi.org/10.3102/0013189X015002004

Simpson, A., \& Linder, S.M. (2014). An examination of mathematics professional development opportunities in early childhood settings. Early Childhood Education Journal, 42, 335-342. https://doi.org/10.1007/s10643-013-0612-7

Stipek, D. J., Givvin, K. B., Salmon, J. M., \& MacGyvers, V. L. (2001). Teachers' beliefs and practices related to mathematics instruction. Teaching and Teacher Education, 17(2), 213-226. https://doi.org/10.1016/S0742-051X(00)00052-4

Takunyaci, M., \& Takunyaci, M. (2014). Preschool Teachers' Mathematics Teaching Efficacy Belief. Procedia-Social and Behavioral Sciences, 152, 673-678. https://doi.org/10.1016/j.sbspro.2014.09.261

Thompson, A. G. (1992). Teachers' beliefs and conceptions: A synthesis of the research. In D. A. Grouws (Ed.), Handbook of research on mathematics teaching and learning (pp. 127-146). NY: Macmillan.

Tsamir, P., Tirosh, D., Levenson, E., Barkai, R., \& Tabach, M. (2014). Early years teachers' concept images and concept definition: triangles, circles and cylinders. ZDM Mathematics Education, 47(3), 497-509. https://doi.org/10.1007/s11858-014-0641-8

Ulusoy, F. (2019). Early-years prospective teachers' definitions, examples and non-examples of cylinder and prism. International Journal of mathematics Teaching and Learning, 20, 149-169.

Whitin, D. J., \& Whitin, P. (2003). Talk counts: Discussing graphs with young children. Teaching Children Mathematics, 10(3), 142150.

Youmans, A., Coombs, A., \& Colgan, L. (2018). Early childhood educators' and teachers' early mathematics education knowledge, beliefs, and pedagogy. Canadian Journal of Education, 41(4), 1079-1104.

Zacharos, K., Koliopoulus, D., Dokimaki, M. M. \& Kossoumi, H. (2007). View of prospective early childhood education teachers, towards mathematics and its instruction. European Journal of Teacher Education, 30(3), 305-318. https://doi.org/10.1080/ 02619760701486134

Zaslow, M., Tout, K., Halle, T., Whittaker, J. V., \& Lavelle, B. (2010). Toward the identification of features of effective professional development for early childhood educators: Literature review. Office of Planning, Evaluation and Policy Development, US Department of Education. Retrieved from https://www2.ed.gov/rschstat/eval/professional-development/literaturereview.pdf 